Check for updates

Cite this: RSC Adv., 2018, 8, 6075

Received 5th December 2017 Accepted 31st January 2018

DOI: $10.1039 / c 7 r a 13048 a$

rsc.li/rsc-advances

\section{Determination of berberine hydrochloride using a fluorimetric method with silica nanoparticles as a probe}

\author{
Qing Liu, (D) Zhihai Xie, ${ }^{*}$ Tao Liu (D) and Jin Fan
}

\begin{abstract}
The interaction of silica nanoparticles $\left(\mathrm{SiO}_{2} \mathrm{NPs}\right)$ with berberine hydrochloride $(\mathrm{BRH})$ was studied in aqueous solution at $\mathrm{pH} 9.0$ and room temperature by using fluorophotometry. Based on a significant enhancement of the fluorescence intensity of the $\mathrm{SiO}_{2} \mathrm{NPs}-\mathrm{BRH}$ aggregates, a spectrofluorimetric method which was simple, sensitive and green was developed for the determination of $\mathrm{BRH}$ in aqueous solution. The linear range of the method was from $2.0-50.0 \mu \mathrm{g} \mathrm{L}^{-1}$ with a detection limit of $0.73 \mu \mathrm{g} \mathrm{L}^{-1}$. There was no interference from the compounds normally used to formulate pharmaceutical tablets. The proposed method was applied to the determination of $\mathrm{BRH}$ in tablets with satisfactory results and good consistency with the results obtained by standard methods.
\end{abstract}

\section{Introduction}

Berberine hydrochloride (BRH, the molecular structure is shown in Fig. 1) is a significant natural isoquinoline alkaloid, which is a key active ingredient in traditional Chinese medicine. It is widely used as an antibacterial and anti-inflammatory drug in pharmaceutical products. ${ }^{\mathbf{1 , 2}}$ Recently, there has been a growing interest in the pharmaceutical activities of $\mathrm{BRH}$ toward infectious diseases, cardiovascular disorders, diabetes, and cancer. $^{3-5}$ Due to the bioactivity and wide potential applications of BRH, many analytical methods have been reported for the its determination, including spectrophotometry, ${ }^{6-8}$ resonance light scattering spectrometry (RLS), ${ }^{\mathbf{9} 10}$ chemiluminescence, ${ }^{\mathbf{1 1}}$ high performance liquid chromatography (HPLC), ${ }^{\mathbf{1 2 , 1 3}}$ capillary electrophoresis, ${ }^{\mathbf{1 4}}$ and electrochemical analysis. ${ }^{15,16}$ Another analytical method gaining importance is fluorophotometry, which is characterized by its high selectivity and sensitivity, simple setup, and convenient operation. Fluorophotometry has been widely applied for the determination of different analytes, including inorganic ions, organic compounds, biomacromolecules, and pharmaceuticals. ${ }^{17-20}$ Furthermore, sensitive fluorophotometry has been reported with metal nanoparticles as probes for the determination of organic compounds and $\mathrm{BRH},{ }^{21-24}$ and receptor molecules such as cyclodextrin, ${ }^{25,26}$ calixarenes, ${ }^{27}$ and cucurbituril ${ }^{28}$ have also been used for the determination of BRH by fluorophotometry. These molecules are capable of interacting with the $\mathrm{BRH}$ molecules through noncovalent intermolecular forces or cavity

Key Laboratory of Synthetic \& Natural Functional Molecular Chemistry of the Ministry of Education, College of Chemistry \& Material Science, Northwest University, No. 1 Xuefu Road, Xi'an, Shaanxi, 710127, China. E-mail: xiezhihai8@163.com; Fax: +86 029-81535026; Tel: +86 029-81535026 encapsulation to form aggregations (or supramolecular complexes). The formation of the aggregation often affects the enhancements or perturbations of the photophysical and photochemical properties of the included guest molecules. ${ }^{29}$

In recent years, silica nanoparticles ( $\left.\mathrm{SiO}_{2} \mathrm{NPs}\right)$ have attracted remarkable interest for biomedical applications because of their special physicochemical properties, such as good solid dispersions, relatively large specific surface areas and biocompatibility, low cost, ease of production, and lack of toxicity. Pure and dye-doped $\mathrm{SiO}_{2}$ NPs were prepared, and their surfaces were modified with enzymes and biocompatible chemical reagents that allow them to function as biosensors and biomarkers. ${ }^{30-33}$ Sensitive and selective fluorescent aptasensors based on $\mathrm{SiO}_{2}$ NPs have been investigated for the determination of biomacromolecules or drugs. ${ }^{34,35}$ Moreover, Fan $^{36}$ reported the use of $\mathrm{SiO}_{2} \mathrm{NPs}$ as a probe for the determination of methylene blue by RLS technique. Nevertheless, the determination of $\mathrm{BRH}$ by fluorophotometry with $\mathrm{SiO}_{2} \mathrm{NPs}$ as a probe has not been reported.

In the present study, a marked increase was found in the fluorescence intensity of $\mathrm{BRH}$ in aqueous media with $\mathrm{SiO}_{2} \mathrm{NPs}$. Therefore, a simple, novel, and green method for the detection of BRH in aqueous solution was developed by fluorophotometry

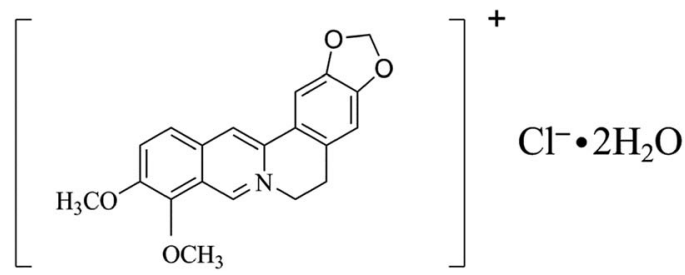

Fig. 1 The chemical structure of berberine hydrochloride. 
with $\mathrm{SiO}_{2} \mathrm{NPs}$ as a probe. In addition, the optimal factors for the determination of $\mathrm{BRH}$ were investigated, and the related mechanisms were also considered. This method was applied for the analysis of practical samples with respectable results.

\section{Experimental}

\subsection{Reagents}

$\mathrm{BRH}$ was purchased from Aladdin Chemical Reagent (Los Angeles, USA) and was used to prepare a $100.0 \mathrm{mg} \mathrm{L}^{-1}$ stock solution. The working solutions were prepared by diluting the stock solution to $100.0 \mu \mathrm{g} \mathrm{L}^{-1}$. $\mathrm{SiO}_{2} \mathrm{NPs}$ (CQ380) were obtained from Emeishan Changqing Chemical New Material Co., Ltd. (China). Acetic acid, boric acid, phosphoric acid, and sodium hydroxide were supplied from the Xi'an Chemical Reagent Factory (Xi'an, China). A Britton-Robinson (BR) buffer solution was prepared by mixing $0.04 \mathrm{~mol} \mathrm{~L}^{-1}$ acetic acid, $0.04 \mathrm{~mol} \mathrm{~L}^{-1}$ boric acid, $0.04 \mathrm{~mol} \mathrm{~L}^{-1}$ phosphoric acid, and $0.2 \mathrm{~mol} \mathrm{~L}^{-1}$ sodium hydroxide solution in specific proportions. All chemicals used in the experiments were of analytical grade and used without further purification. Deionized water was used for preparing all samples and solutions.

\subsection{Apparatus}

The instruments used in this study were as follows: F-4500 spectrofluorophotometer (Hitachi, Japan); UV-1700 spectrophotometer (Shimadzu, Japan); H-600 transmission electron microscope (Hitachi, Japan); DB-525 Zeta Potential Analyzer (Brookhaven, USA); pHs-3C digital pH meter (Shanghai Lei Ci Device Works, China) with a glass electrode (Model E-201-C); and magnetic stirrer (Gongyi Yuhua Instrument Factory, China).

\subsection{Preparation of $\mathrm{SiO}_{2} \mathrm{NPs}$ dispersion}

Exactly $0.10 \mathrm{~g}$ of $\mathrm{SiO}_{2} \mathrm{NPs}$ was weighed out and added into $200.0 \mathrm{~mL}$ of deionized water under vigorous stirring for $10 \mathrm{~min}$, and then the mixture was placed in an ultrasonic bath for $30 \mathrm{~min}$ at room temperature to completely disperse the $\mathrm{SiO}_{2}$ NPs. The concentration of the dispersion was $0.05 \%$.

\subsection{Preparation of samples}

The sugar coating was carefully removed from 10 tablets and the contents were carefully pulverized. The powders were then thoroughly mixed. A portion of the mixed powders was accurately weighed and placed in a $100 \mathrm{~mL}$ volumetric flask. The powder was dissolved by addition of deionized water up to the mark and sonication for $10 \mathrm{~min}$, and the solution was then filtered. The first $30 \mathrm{~mL}$ of the filtrate were discarded, a portion of the remaining filtered sample solution was diluted to the mark in a $100 \mathrm{~mL}$ volumetric flask, and this solution was analyzed according to the general procedure.

\subsection{General procedure}

The general procedure for determination of $\mathrm{BRH}$ is as follows: $0.8 \mathrm{~mL}$ of $0.05 \% \mathrm{SiO}_{2} \mathrm{NPs}$ dispersion, $0.5 \mathrm{~mL}$ of $\mathrm{BR}$ buffer solution ( $\mathrm{pH} 9.0)$, and a certain amount of BRH working solution were added into a $10.0 \mathrm{~mL}$ volumetric flask, diluted to the mark with deionized water, and sonicated for $2 \mathrm{~min}$. The resulting solution was left at room temperature for $30 \mathrm{~min}$, and then the fluorescence intensity was measured at $540 \mathrm{~nm}$ with an excitation wavelength of $355 \mathrm{~nm}$. The enhanced fluorescence intensities of the solutions were calculated by the following equation: $\Delta I_{\mathrm{F}}=I_{\mathrm{F}}-I_{\mathrm{Fo}}$ (in which $I_{\mathrm{F}}$ and $I_{\mathrm{Fo}}$ are the fluorescence intensities of the $\mathrm{SiO}_{2} \mathrm{NPs}$ in the presence and absence of $\mathrm{BRH}$ ). All experiments were conducted at room temperature.

\section{Results and discussion}

\subsection{Absorption spectra}

The absorption spectra of $\mathrm{BRH}$ and the $\mathrm{SiO}_{2} \mathrm{NPs}-\mathrm{BRH}$ aggregates are shown in Fig. 2. The absorbance of the solution gradually decreased and the absorption spectrum shifted toward longer wavelength $(2-5 \mathrm{~nm})$ with addition of $\mathrm{SiO}_{2} \mathrm{NPs}$, as well as there were three obvious isosbestic points $(354 \mathrm{~nm}$, $389 \mathrm{~nm}, 435 \mathrm{~nm})$. This corresponds to the absorption of aggregates which is clearly different from unaggregated. In addition, the excitation spectrum at $450 \mathrm{~nm}$ was also observed except for $355 \mathrm{~nm}$ (Fig. 3A). The phenomenons might be because the positive charge of $\mathrm{BRH}$ causes it to be adsorbed on the surface of the $\mathrm{SiO}_{2} \mathrm{NPs}$ to form $\mathrm{SiO}_{2} \mathrm{NPs}-\mathrm{BRH}$ aggregates. ${ }^{37}$

\subsection{Excitation and emission spectra}

The excitation and emission spectra were measured according to the general procedure. The results are shown in Fig. 3. The excitation wavelengths were located at 355 and $450 \mathrm{~nm}$, and the emission wavelengths were at $540 \mathrm{~nm}$. The fluorescence intensities of the BRH and $\mathrm{SiO}_{2} \mathrm{NPs}$ on their own were very small at $540 \mathrm{~nm}$ in aqueous solution. However, when $\mathrm{SiO}_{2} \mathrm{NPs}$ was added to the aqueous solution of $\mathrm{BRH}$, the fluorescence intensity was significantly enhanced. Because $\mathrm{BRH}$ molecules were bound to the surfaces of the $\mathrm{SiO}_{2} \mathrm{NPs}$ and protected as $\mathrm{SiO}_{2} \mathrm{NPs}-$ $\mathrm{BRH}$ aggregates, the fluorescence intensity increased.

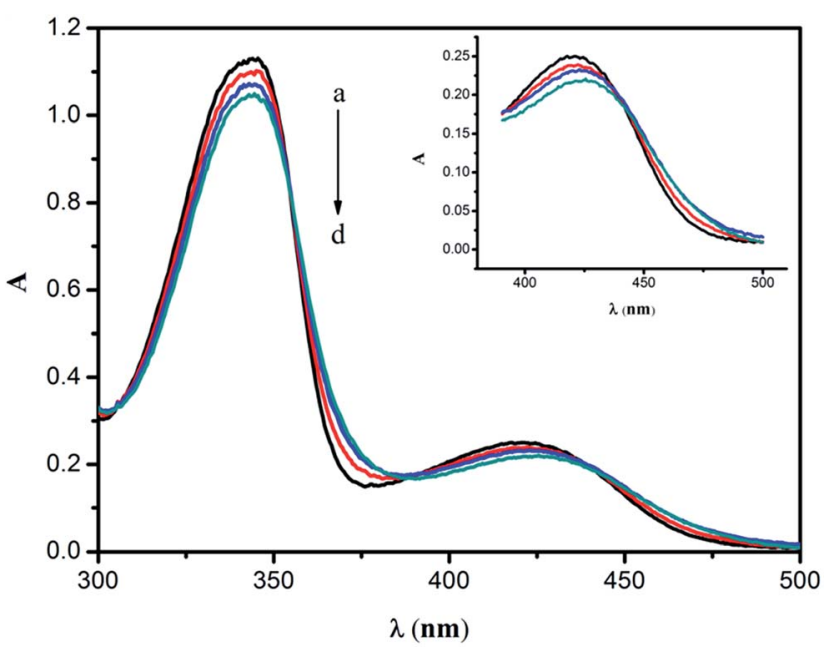

Fig. 2 Absorption spectra. Conditions: (a) BRH, $20 \mathrm{mg} \mathrm{L}^{-1}$; (b-d) a + $\mathrm{SiO}_{2} \mathrm{NPs}(0.01,0.02$, and $0.03 \%) ; \mathrm{pH} 9.0$. 

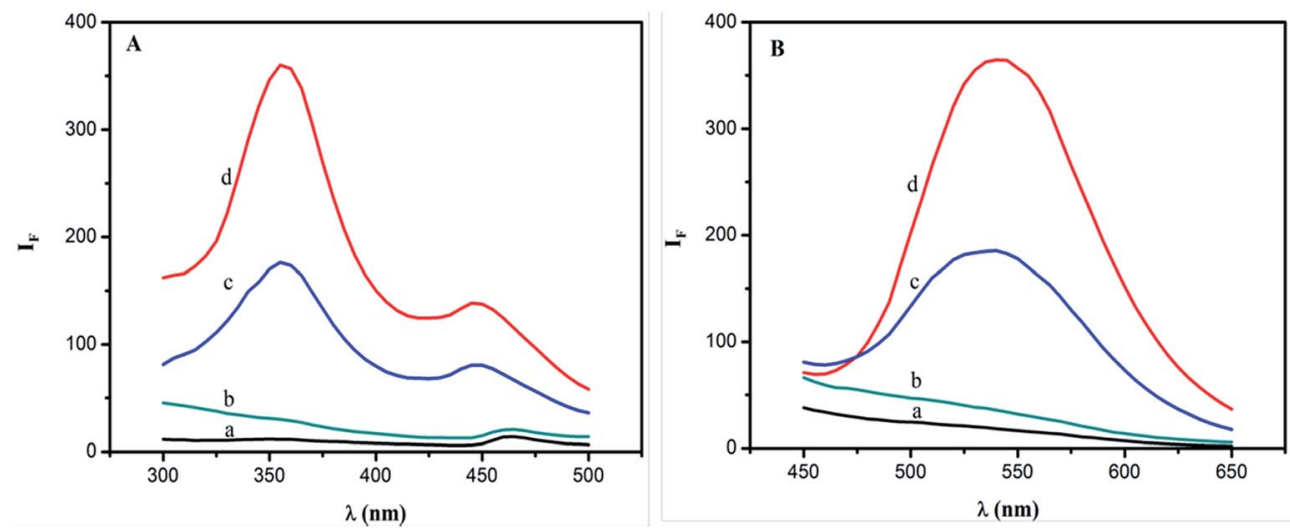

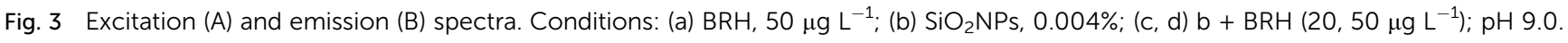

Therefore, the concentration of $\mathrm{BRH}$ could be determined by fluorophotometry by using $\mathrm{SiO}_{2} \mathrm{NPs}$ as a probe.

\subsection{TEM images and the dynamic light scattering (DLS)}

The TEM images of $\mathrm{SiO}_{2} \mathrm{NPs}$ and the $\mathrm{SiO}_{2} \mathrm{NPs}-\mathrm{BRH}$ aggregates are shown in Fig. 4. When the $\mathrm{SiO}_{2} \mathrm{NPs}$ reacted with $\mathrm{BRH}$ under the optimal conditions, the size increased as the aggregates of the $\mathrm{BRH}$ and $\mathrm{SiO}_{2} \mathrm{NPs}$ were formed. The $\mathrm{SiO}_{2} \mathrm{NPs}-\mathrm{BRH}$ aggregates exhibit tufted shapes as shown in Fig. 4B.

The size distribution of $\mathrm{SiO}_{2} \mathrm{NPs}$ and $\mathrm{SiO}_{2} \mathrm{NPs}-\mathrm{BRH}$ aggregates were measured by the DLS in order to confirm the formation of aggregates. As shown in Fig. 4C and D, the average diameters of the $\mathrm{SiO}_{2} \mathrm{NPs}$ in the solution were about $136.2 \mathrm{~nm}$ in the absence of $\mathrm{BRH}$ and they were prominently increased by roughly $90 \mathrm{~nm}$ at the addition of $\mathrm{BRH}$ due aggregation occurred.

\subsection{Effect of $\mathbf{p H}$}

The $\mathrm{pH}$ of the solution plays an important role in the interaction between the $\mathrm{BRH}$ and $\mathrm{SiO}_{2} \mathrm{NPs}$, because it affects the surface charge properties of the $\mathrm{SiO}_{2} \mathrm{NP}_{\mathrm{S}}$. Hence, the influence of the $\mathrm{pH}$ on $\Delta I_{\mathrm{F}}$ was studied over a wide range of $\mathrm{pH}$ from 6 to 11. The results are shown in Fig. 5. The maximum value of $\Delta I_{\mathrm{F}}$ was obtained at $\mathrm{pH}$ 9.0. Therefore, BR buffer with $\mathrm{pH} 9.0$ was used for further experiments.
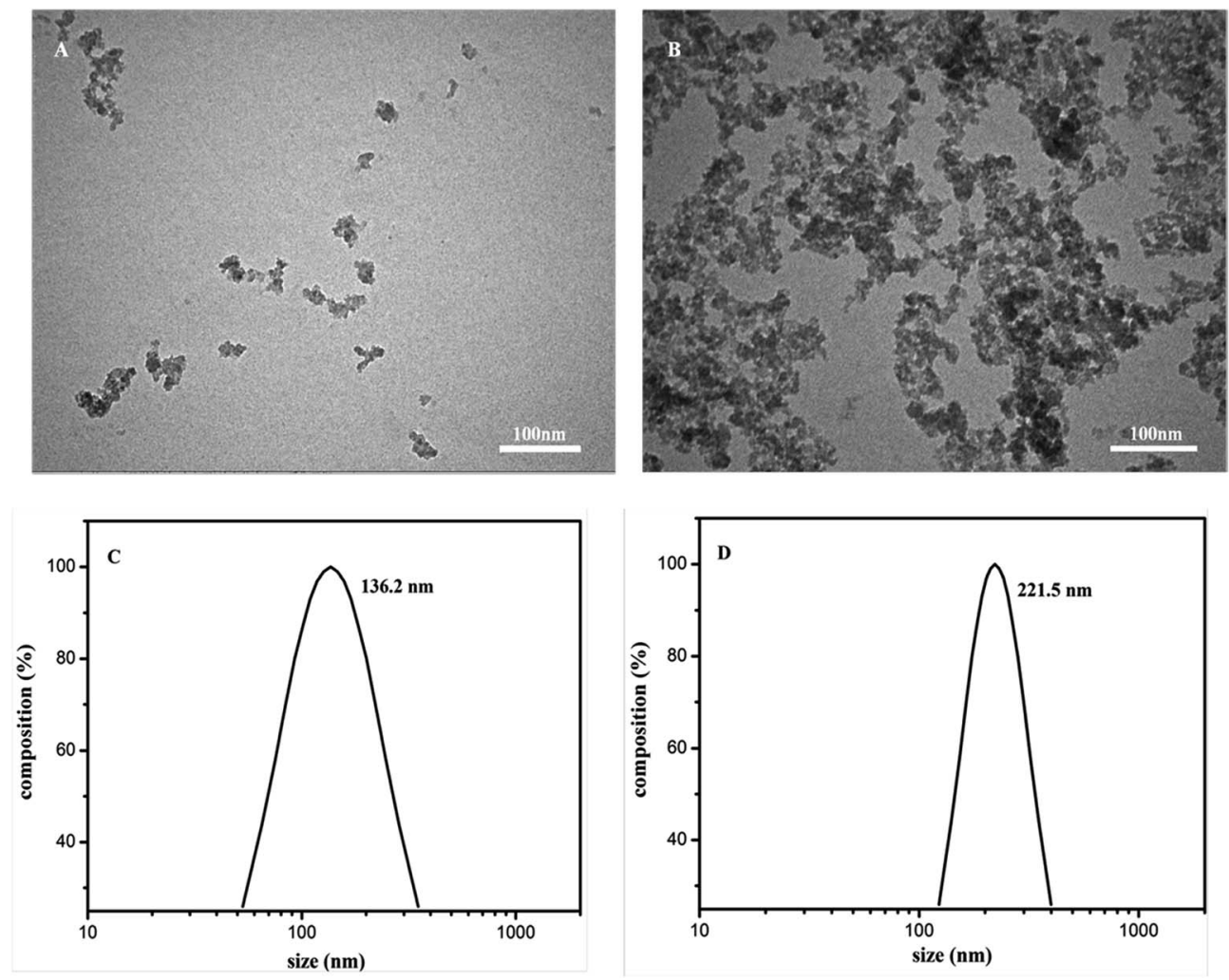

Fig. 4 TEM images of $\mathrm{SiO}_{2} \mathrm{NPs}(\mathrm{A})$ and $\mathrm{SiO}_{2} \mathrm{NPs}-\mathrm{BRH}$ (B). The size distribution curve of $\mathrm{SiO}_{2} \mathrm{NPs}(\mathrm{C})$ and $\mathrm{SiO}{ }_{2} \mathrm{NPs}-\mathrm{BRH}(\mathrm{D})$. 


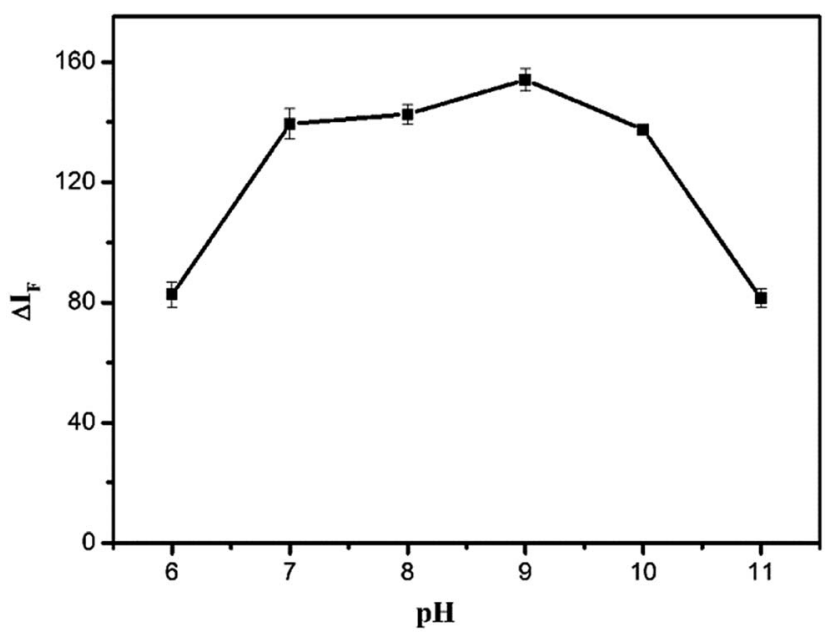

Fig. 5 Effect of $\mathrm{pH}$ on $\Delta /$ F. Conditions: $\mathrm{SiO}_{2} \mathrm{NPs}$ : $0.004 \%$; $\mathrm{BRH}$ : $20.0 \mu \mathrm{g} \mathrm{L}^{-1}$.

\subsection{Effect of reaction time and temperature}

The effects of different reaction times and temperatures were investigated. As shown in Fig. 6, the $\Delta I_{\mathrm{F}}$ reached a maximum value after $30 \mathrm{~min}$ and remained constant for $2 \mathrm{~h}$. The temperature test results (Fig. 7) indicated that the fluorescence intensity of the solution remained stable between 10 and $40{ }^{\circ} \mathrm{C}$. Thus, $30 \mathrm{~min}$ of reaction time and room temperature were selected for further research.

\subsection{Effect of concentration of $\mathrm{SiO}_{2} \mathrm{NPs}$}

The effect of the concentration of $\mathrm{SiO}_{2} \mathrm{NPS}$ on the $\Delta I_{\mathrm{F}}$ value was investigated. The linear regression equations and $R^{2}$ values are given in Fig. 8. When the concentration of $\mathrm{SiO}_{2} \mathrm{NPs}$ was greater than $0.004 \%$, the reagent blank increased and the linear range narrowed. If the concentration of $\mathrm{SiO}_{2} \mathrm{NPs}$ was lower than $0.004 \%$, the linear range was relatively narrow because of incompletion of the interaction between $\mathrm{BRH}$ and the $\mathrm{SiO}_{2} \mathrm{NPs}$.

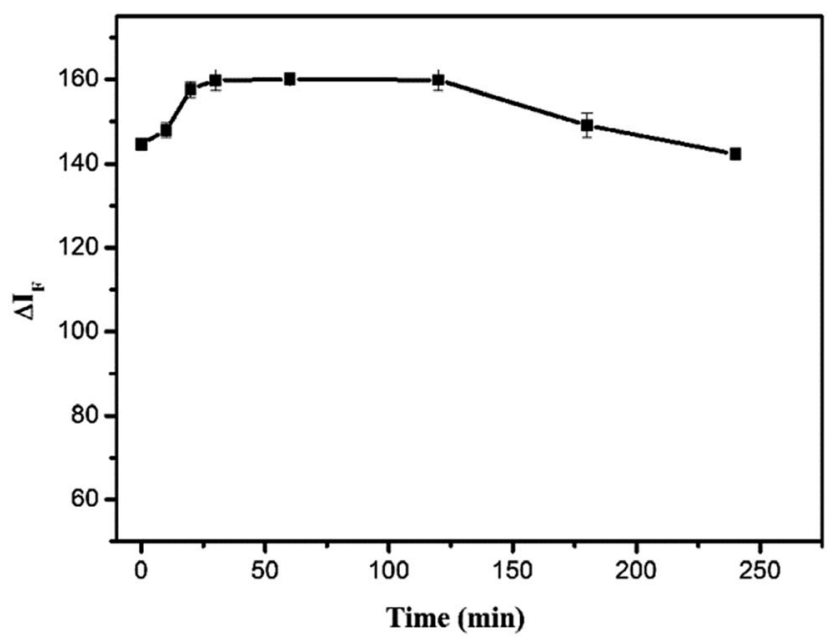

Fig. 6 Effect of reaction time on $\Delta /_{\mathrm{F}}$. Conditions: $\mathrm{SiO}_{2} \mathrm{NPS}$ : $0.004 \%$; BRH: $20.0 \mu \mathrm{g} \mathrm{L}^{-1} ; \mathrm{pH} 9.0$.

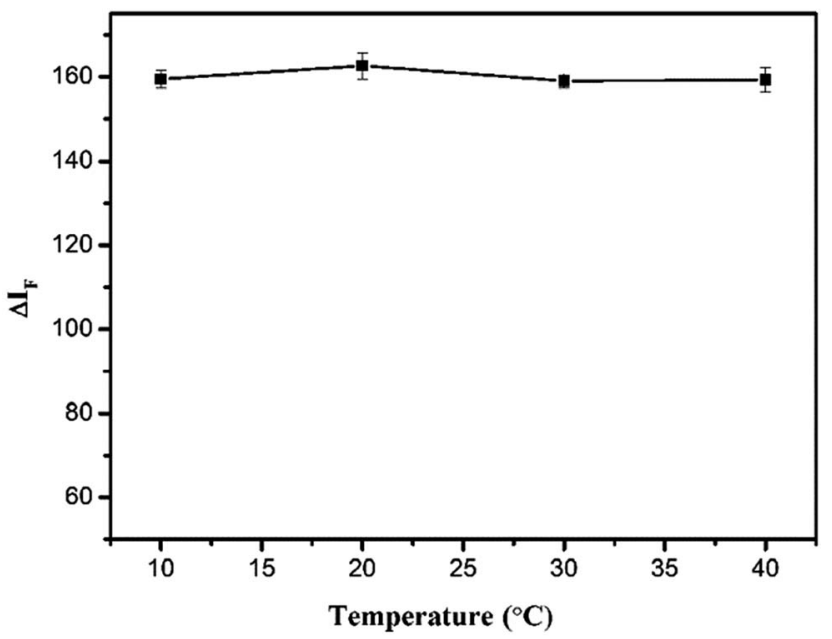

Fig. 7 Effect of reaction temperature on $\Delta /_{\text {F. }}$ Conditions: $\mathrm{SiO}_{2} \mathrm{NPS}$ : $0.004 \%$; BRH: $20.0 \mu \mathrm{g} \mathrm{L}^{-1} ; \mathrm{pH} 9.0$.

Therefore, $0.004 \%$ was selected as a suitable concentration for further experiments.

\subsection{Effect of ionic strength}

The influence of ionic strength on the $\Delta I_{\mathrm{F}}$ value was researched by adding different amounts of $\mathrm{NaCl}$ into the $\mathrm{SiO}_{2} \mathrm{NPs}-\mathrm{BRH}$ solutions. As shown in Fig. 9, when the concentration of $\mathrm{NaCl}$ was lower than $150 \mathrm{mg} \mathrm{L}^{-1}$, the $\Delta I_{\mathrm{F}}$ value remained constant. By contrast, when the concentration of $\mathrm{NaCl}$ was higher than $150 \mathrm{mg} \mathrm{L}^{-1}$, the $\Delta I_{\mathrm{F}}$ value reduced as the concentration of $\mathrm{NaCl}$ increased. This could be interpreted as the shielding and competing effects of $\mathrm{Cl}^{-}$and $\mathrm{Na}^{+}$on the binding process between the $\mathrm{BRH}$ and $\mathrm{SiO}_{2} \mathrm{NPs}$.

\subsection{Effect of coexisting ions}

Under the optimal experimental conditions, the interference of coexisting ions in the solution was investigated for the

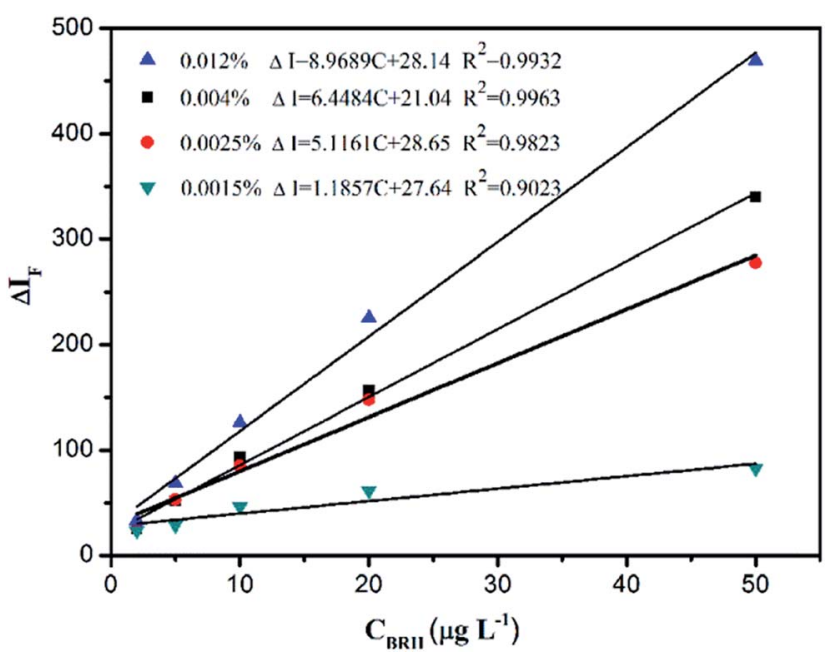

Fig. 8 Effect of $\mathrm{SiO}_{2} \mathrm{NPs}$ concentration. Conditions: pH 9.0. 


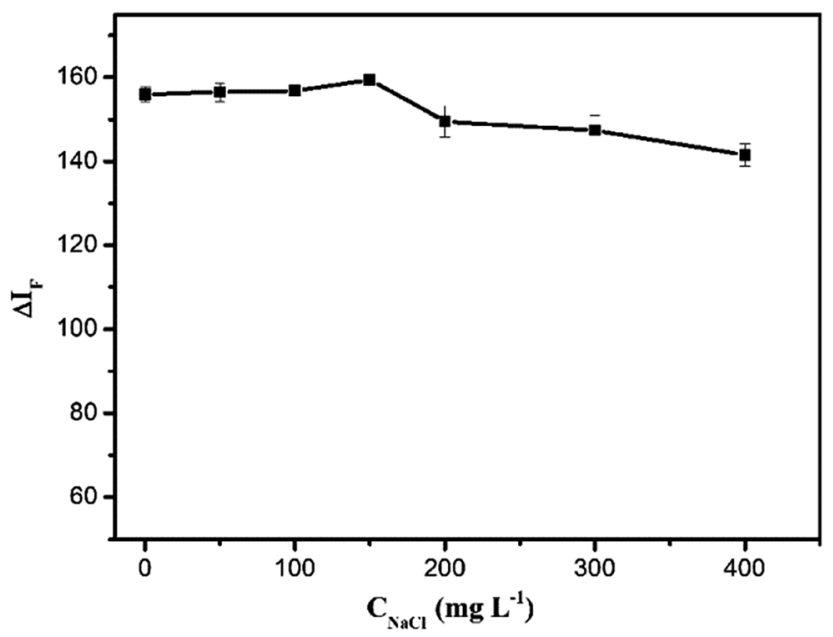

Fig. 9 Effect of ionic strength. Conditions: $\mathrm{SiO}_{2} \mathrm{NPs}$ : $0.004 \%$; $\mathrm{BRH}$ : $20.0 \mu \mathrm{g} \mathrm{L}^{-1}$; $\mathrm{pH} 9.0$.

determination of BRH. The experiments were carried out by fixing the concentration of BRH at $10.0 \mu \mathrm{g} \mathrm{L}^{-1}$, and then the fluorescence intensities were recorded before and after addition of coexisting ions to the solution. The permitted relative deviation was less than $\pm 5 \%$. The experimental results are listed in Table 1. Most of the coexisting ions did not interfere with the determination of BRH. Only $\mathrm{Mg}^{2+}, \mathrm{Ca}^{2+}, \mathrm{Co}^{2+}, \mathrm{Ni}^{2+}$ and $\mathrm{Cu}^{2+}$ ions showed interference with the determination of $\mathrm{BRH}$ at low concentrations. In order to avoid interference from the metal ions, $1.0 \mathrm{~mL}$ of the chelating agent ethylene diamine tetraacetic acid (EDTA; $100.0 \mathrm{mg} \mathrm{L}^{-1}$ ) was added.

\subsection{Working curve and detection limit}

According to the general procedure above, when a certain amount of BRH working solution was added, the fluorescence intensities of the solution and reagent blank were measured at $540 \mathrm{~nm}$ with an excitation wavelength of $355 \mathrm{~nm}$. As shown in Fig. 10A, the fluorescence intensity increased with an increasing concentration of BRH. There was a good linear relationship (Fig. 10B) between the $\Delta I_{\mathrm{F}}$ value and the concentration of BRH in the range of $2.0-50.0 \mu \mathrm{g} \mathrm{L}{ }^{-1}$. The linear equation was $\Delta I_{\mathrm{F}}=6.4484 c+21.04\left(c\right.$ in $\left.\mu \mathrm{g} \mathrm{L}{ }^{-1}\right)$, with $R^{2}$ $=0.9963$. The relative standard deviation is $1.58 \%(n=11)$. Under the optimal conditions, the limit of detection (LOD; $3 \sigma /$ k) was $0.73 \mu \mathrm{g} \mathrm{L}^{-1}$.

Table 1 Interference of coexisting ions $\left([\mathrm{BRH}]=10.0 \mu \mathrm{g} \mathrm{L}^{-1}\right)$

\begin{tabular}{|c|c|c|c|c|c|}
\hline $\begin{array}{l}\text { Interfering } \\
\text { ions }\end{array}$ & Concentration $\left(\mathrm{mg} \mathrm{L}^{-1}\right)$ & Relative error (\%) & Interfering ions & Concentration $\left(\mathrm{mg} \mathrm{L}^{-1}\right)$ & Relative error (\%) \\
\hline $\mathrm{Na}^{+}$ & 150 & 5.0 & $\mathrm{Co}^{2+}$ & $0.1,0.4^{a}$ & 1.7 \\
\hline $\mathrm{NH}_{4}^{+}$ & 30 & 1.1 & $\mathrm{NO}_{3}^{-}$ & 100 & 3.7 \\
\hline $\mathrm{Mg}^{2+}$ & $1,10^{a}$ & 3.8 & $\mathrm{SO}_{4}{ }^{2-}$ & 100 & -2.9 \\
\hline $\mathrm{Ca}^{2+}$ & $1.5,10^{a}$ & 2.2 & $\mathrm{Cl}^{-}$ & 150 & 5.0 \\
\hline $\mathrm{Mn}^{2+}$ & 0.8 & 2.6 & Glucose & 200 & -1.0 \\
\hline $\mathrm{Al}^{3+}$ & 0.8 & 3.2 & Tragantine & 80 & -1.9 \\
\hline $\mathrm{Fe}^{3+}$ & 1 & 4.7 & Urea & 8 & 5.0 \\
\hline $\mathrm{Fe}^{2+}$ & 1 & 1.7 & & & \\
\hline
\end{tabular}

${ }^{a}$ The acceptable concentration of coexisting ions after addition of EDTA.
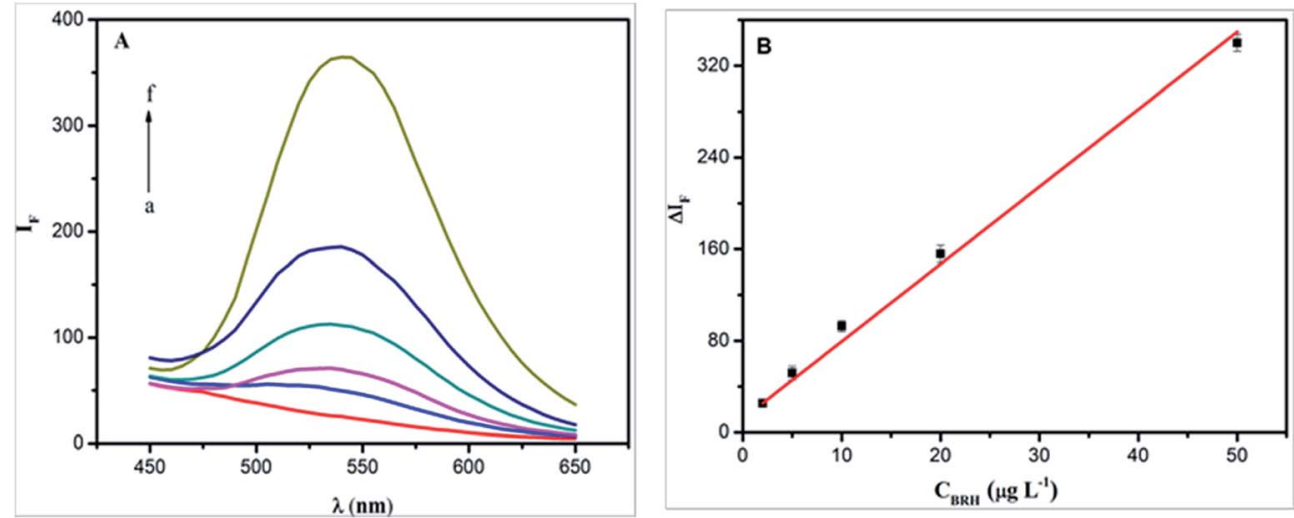

Fig. 10 The fluorescence spectra of $\mathrm{SiO}_{2} \mathrm{NPs}-\mathrm{BRH}(\mathrm{A})$ and calibration curve for determination of $\mathrm{BRH}$ (B). Conditions: $\mathrm{SiO} \mathrm{O}_{2} \mathrm{NPs}$ : $0.004 \%$; $\mathrm{BRH}$ : (a-f): 0, 2.0, 5.0, 10.0, 20.0, and $50.0 \mu \mathrm{g} \mathrm{L}^{-1} ; \mathrm{pH} 9.0$. 


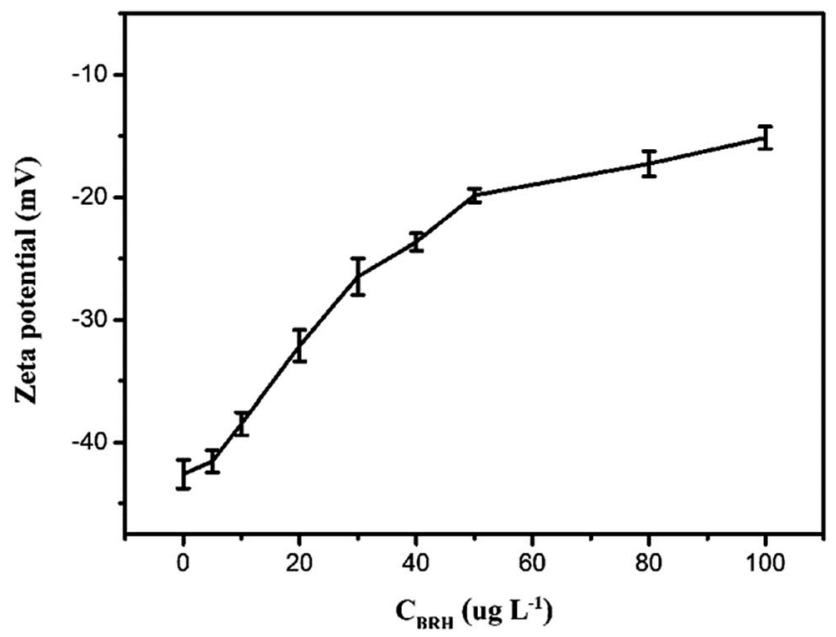

Fig. 11 Zeta potential curve of $\mathrm{SiO}_{2} \mathrm{NPs}-\mathrm{BRH}$. Conditions: $\mathrm{SiO}_{2} \mathrm{NPs}$ : $0.004 \%$; $B R H: 0,5.0,10.0,20.0,30.0,40.0,50.0,80.0$ and $100.0 \mu \mathrm{g} \mathrm{L}^{-1} ; \mathrm{pH} 9.0$.

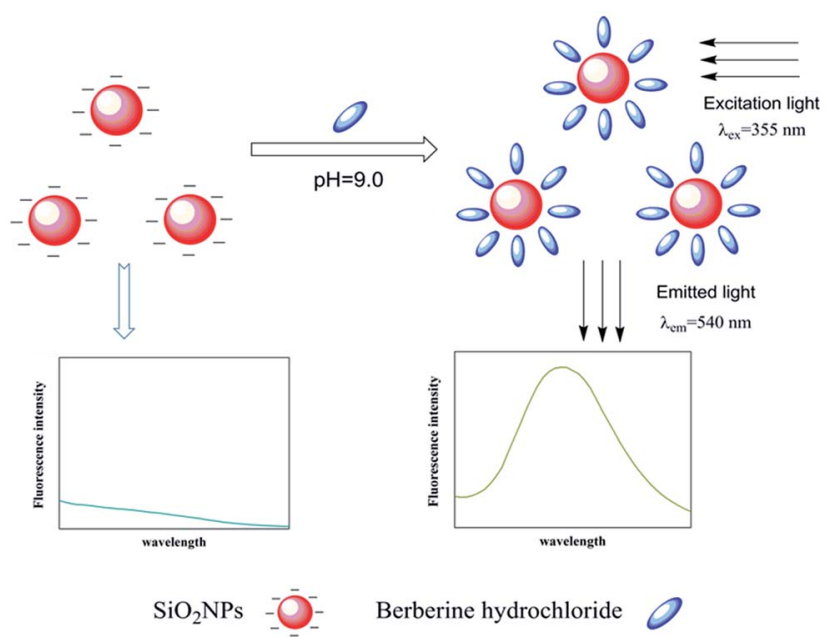

Fig. 12 Schematic illustration of the possible procedure for the detection of $\mathrm{BRH}$.

\subsection{Mechanism of reaction}

It is well known that BRH is almost nonfluorescent in water, the nonfluorescent behaviour could either due to low lying intramolecular charge transfer state or vibrational coupling of excited state with water molecules, but it fluoresces appreciably when it is dissolved in some organic solvents, or incorporated in cyclodextrins, ${ }^{25,26}$ calixarenes, ${ }^{27}$ and cucurbits. ${ }^{38}$ In the paper, it was found that the fluorescence intensity of $\mathrm{BRH}$ was increased in aqueous media with $\mathrm{SiO}_{2} \mathrm{NPs}$. In order to further investigate interaction between $\mathrm{SiO}_{2} \mathrm{NPs}$ and $\mathrm{BRH}$, the zeta potential of the $\mathrm{SiO}_{2} \mathrm{NPs}-\mathrm{BRH}$ solution was measured and the results were shown in Fig. 11. The zeta potential of the $\mathrm{SiO}_{2} \mathrm{NPs}$ was $-42.6 \mathrm{mV}$ because of dissociation of silicon hydroxyl on the surface. The zeta potential move gradually toward zero with the increase in $\mathrm{BRH}$ with positive charges. The binding of $\mathrm{SiO}_{2} \mathrm{NPs}$ with $\mathrm{BRH}$ would make the surface of $\mathrm{SiO}_{2} \mathrm{NPs}-\mathrm{BRH}$ aggregates more hydrophobic. The results indicated that the aggregation of $\mathrm{SiO}_{2} \mathrm{NPS}-\mathrm{BRH}$ was the neutralization of charges upon electrostatic interaction and increase of hydrophobicity. The marked enhancement of fluorescence intensity is due to aggregation induced emission enhancement. ${ }^{39-41} \mathrm{~A}$ schematic diagram of the possible procedure is presented in Fig. 12.

\section{Application}

To demonstrate the viability of this method, the developed procedure was used for the determination of $\mathrm{BRH}$ in real samples. The reliability and accuracy of the method was proved by recovery tests. The determination of each sample was conducted six times in parallel. The recoveries were between 97.06 and $101.6 \%$. The determination results were compared with the results from the pharmaceutical method ${ }^{42}$ through a $t$-test analysis. There was no significant difference between the proposed and standard method under the confidence level of 95\%. The results are shown in Table 2 .

In addition, this method was also compared with previous methods for BRH determination. The comparison is given in Table 3 and indicates that this method has better sensitivity than most other methods.

Table 2 Results of determination of BRH in tablets $(n=6)$

\begin{tabular}{|c|c|c|c|c|c|c|}
\hline \multirow[t]{2}{*}{$1^{b}$} & 0 & $18.71 \pm 0.309$ & - & 99.50 & $100.4 \pm 1.66$ & 1.35 \\
\hline & 15.0 & $33.27 \pm 0.541$ & $97.06 \pm 3.60$ & - & - & - \\
\hline \multirow[t]{2}{*}{$2^{c}$} & 0 & $14.39 \pm 0.298$ & - & 49.33 & $50.38 \pm 1.04$ & 2.46 \\
\hline & 10.0 & $24.42 \pm 0.258$ & $100.3 \pm 3.33$ & - & - & - \\
\hline & 10.0 & $27.20 \pm 0.559$ & $101.4 \pm 5.54$ & - & - & - \\
\hline & 15.0 & $31.75 \pm 0.545$ & $97.94 \pm 3.64$ & - & - & - \\
\hline
\end{tabular}

${ }^{a}$ Mean \pm standard deviation $(n=6) .{ }^{b}$ Berberine hydrochloride tablets, Chengdu Jinhua Pharmaceutical Co., Ltd. (Chengdu, China). ${ }^{c}$ Compound ancklandia and berberine tablets, Grand Pharmaceutical Huangshi Feiyun Pharmaceutical Co., Ltd. (Hubei, China). ${ }^{d}$ Amaranth berberine capsule, Fuzhou Neptunus Jinxiang Chinese Medicine Pharmaceutical Co., Ltd. (Fuzhou, China). 
Table 3 Comparison of this work with some of other reported methods for $\mathrm{BRH}$ determination

\begin{tabular}{|c|c|c|c|c|}
\hline Method & Probe & $\operatorname{LDR}^{e}\left(\mu \mathrm{g} \mathrm{L}{ }^{-1}\right)$ & $\begin{array}{l}\text { LOD } \\
\left(\mu \mathrm{g} \mathrm{L}^{-1}\right)\end{array}$ & Ref. \\
\hline $\mathrm{UV}^{a}$ & - & $118-706.0$ & - & 6 \\
\hline UV & AuNPs & $240-860$ & 60 & 8 \\
\hline HPLC & - & $50-5.0 \times 10^{4}$ & 10 & 13 \\
\hline $\mathrm{RRS}^{b}$ & AuNPs & $1.33-240.0$ & 0.40 & 10 \\
\hline $\mathrm{CE}^{c}$ & Cyclodextrin & $100-13.4 \times 10^{3}$ & 15.7 & 14 \\
\hline $\mathrm{EC}^{d}$ & - & $58.8-7.06 \times 10^{3}$ & 32.9 & 15 \\
\hline Fluorescence & Cucurbit[7]uril & $3.20-2.00 \times 10^{3}$ & 1.1 & 28 \\
\hline Fluorescence & Cucurbit[7]uril & $7.43-11.2 \times 10^{3}$ & 4.2 & 38 \\
\hline Fluorescence & Cyclodextrin & $12.8-1.00 \times 10^{4}$ & 3.6 & 25 \\
\hline Fluorescence & Cyclodextrin & $94.1-4.71 \times 10^{3}$ & 11.8 & 26 \\
\hline Fluorescence & $\mathrm{SiO}_{2} \mathrm{NPs}$ & $2.0-50.0$ & 0.73 & This work \\
\hline
\end{tabular}

${ }^{a}$ Ultraviolet absorption. ${ }^{b}$ Resonance Rayleigh scattering. ${ }^{c}$ Capillary electrophoresis. ${ }^{d}$ Electrochemical analysis. ${ }^{e}$ Linear dynamic range.

\section{Conclusions}

This paper describes the development of a simple and novel fluorimetric method based on the increase in the fluorescence intensity of $\mathrm{BRH}$ after addition of $\mathrm{SiO}_{2}$ NPs. The mechanism of the enhancement of fluorescence intensity has been discussed and the effects of the key experimental parameters on the fluorescence enhancement have also been described in detail. The proposed method allows the direct determination of $\mathrm{BRH}$ in aqueous solution with good accuracy, sensitivity, and tolerance. The amount of $\mathrm{BRH}$ can be measured without any complicated or time-consuming sample pretreatment processes. Compared with other reported methods, the proposed method is more sensitive, rapid, and environmentally friendly. This method was used for the detection of $\mathrm{BRH}$ in actual samples with satisfactory results.

\section{Conflicts of interest}

There are no conflicts of interest to declare.

\section{References}

1 S. Bandyopadhyay, P. H. Patra, A. Mahanti, D. K. Mondal, P. Dandapat, S. Bandyopadhyay, I. Samanta, C. Lodh, A. K. Bera, D. Bhattacharyya, M. Sarkar and K. K. Baruah, Asian Pac. J. Trop. Med., 2013, 6, 315-319.

2 R. Gautam and S. M. Jachak, Med. Res. Rev., 2009, 29, 767820.

3 L. M. Xia and M. H. Luo, Chronic Dis. Transl. Med., 2015, 1, 231-235.

4 C. M. Tian, X. Jiang, X. X. OuYang, Y. O. Zhang and W. D. Xie, Chin. J. Nat. Med., 2016, 14, 518-526.

5 H. P. Kuo, T. C. Chuang, M. H. Yeh, S. C. Hsu, T. D. Way, P. Y. Chen, S. S. Wang, Y. H. Chang, M. C. Kao and J. Y. Liu, J. Agric. Food Chem., 2011, 59, 8216-8224.

6 T. Sakai, Analyst, 1983, 108, 608-614.

7 T. Sakai, Analyst, 1991, 116, 187-190.
8 Z. W. Hu, M. S. Xie, D. T. Yang, D. Chen, J. Y. Jian, H. B. Li, K. S. Yuan, Z. J. Jiang and H. B. Zhou, RSC Adv., 2017, 7, 34746-34754.

9 X. B. Pang and C. Z. Huang, J. Pharm. Biomed. Anal., 2004, 35, 185-191.

10 S. P. Liu, Z. Yang, Z. F. Liu, J. T. Liu and Y. Shi, Anal. Chim. Acta, 2006, 572, 283-289.

11 P. Biparva, S. M. Abedirad, S. Y. Kazemi and M. Shanehsaz, Sens. Actuators, B, 2016, 234, 278-285.

12 G. H. Liu, W. He, H. Cai, X. M. Sun, W. E. Hou, M. N. Lin, Z. Y. Xie and Q. F. Liao, Anal. Methods, 2014, 6, 2998-3008.

13 P. L. Tsai and T. H. Tsai, J. Chromatogr. A, 2002, 961, 125130.

14 S. Uzasci and F. B. Erim, J. Chromatogr. A, 2014, 1338, 184187.

15 A. Geto, M. Pita, A. L. De Lacey, M. Tessema and S. Admassie, Sens. Actuators, B, 2013, 183, 96-101.

16 J. F. Song, Y. Y. He and W. Guo, J. Pharm. Biomed. Anal., 2002, 28, 355-363.

17 H. M. Al-Saidi and M. S. El-Shahawi, Spectrochim. Acta, Part A, 2015, 138, 736-742.

18 J. R. Bi, H. T. Wang, T. Kamal, B. W. Zhu and M. Q. Tan, RSC Adv., 2017, 7, 30481-30487.

19 G. Q. Gong, Z. X. Zong and Y. M. Song, Spectrochim. Acta, Part A, 1999, 55, 1903-1907.

20 M. X. Gao, J. L. Xu, Y. F. Li and C. Z. Huang, Anal. Methods, 2013, 5, 673-677.

21 Y. Y. Liu, H. C. Li, B. Guo, L. J. Wei, B. Chen and Y. Y. Zhang, Biosens. Bioelectron., 2017, 91, 734-740.

22 P. J. Ni, Y. J. Sun, S. Jiang, W. D. Lu, Y. L. Wang and Z. Li, Sens. Actuators, B, 2017, 240, 651-656.

$23 \mathrm{X}$. Y. Zheng, T. M. Yao, Y. Zhu and S. Shi, Biosens. Bioelectron., 2015, 66, 103-108.

24 S. Liang, Y. F. Kuang, F. F. Ma, S. Chen and Y. F. Long, Biosens. Bioelectron., 2016, 85, 758-763.

25 F. Liu, H. L. Liang, K. H. Xu, L. L. Tong and B. Tang, Talanta, 2007, 74, 140-145.

26 Y. Yang, X. Yang, C. X. Jiao, H. F. Yang, Z. M. Liu, G. L. Shen and R. Q. Yu, Anal. Chim. Acta, 2004, 513, 385-392.

27 M. Megyesi and L. Biczok, Chem. Phys. Lett., 2006, 424, 7176.

28 Y. P. Li, H. Wu and L. M. Du, Chin. Chem. Lett., 2009, 20, 322325.

29 K. A. Connors, Chem. Rev., 1997, 97, 1325-1357.

30 I. Miletto, A. Gilardino, P. Zamburlin, S. Dalmazzo, D. Lovisolo, G. Caputo, G. Viscardi and G. Martra, Dyes Pigm., 2010, 84, 121-127.

31 S. Liang, K. Shephard, D. T. Pierce and X. J. Zhao, Nanoscale, 2013, 5, 9365-9373.

32 A. Hemadi, A. Ekrami, H. Oormazdi, A. R. Meamar, L. Akhlaghi, A. R. Samarbaf-Zadeh and E. Razmjou, Acta Trop., 2015, 145, 26-30.

33 M. Qhobosheane, S. Santra, P. Zhang and W. H. Tan, Analyst, 2001, 126, 1274-1278.

34 K. Abnous, N. M. Danesh, A. S. Emrani, M. Ramezani and S. M. Taghdisi, Anal. Chim. Acta, 2016, 917, 71-78. 
35 A. S. Emrani, S. M. Taghdisi, N. M. Danesh, S. H. Jalalian, M. Ramezani and K. Abnous, Anal. Methods, 2015, 7, 38143818.

36 J. Fan, Z. H. Xie, X. X. Teng and Y. Zhang, Chin. Chem. Lett., 2017, 28, 1104-1110.

37 M. Megyesi and L. Biczók, J. Phys. Chem. B, 2007, 111, 56355639.

38 N. Dong, L. N. Cheng, X. L. Wang, Q. Li, C. Y. Dai and Z. Tao, Talanta, 2011, 84, 684-689.
39 A. Gopi, A. Vindhyasarumi and K. Yoosaf, $R S C A d v ., 2015,5$, 47813-47819.

40 C. J. Kassl and F. C. Pigge, Tetrahedron Lett., 2014, 55, 48104813.

41 F. Qiao, L. Zhang, Z. Lian, Z. Yuan, C. Y. Yan, S. P. Zhuo and Z. Y. Zhou, J. Photochem. Photobiol., A, 2017, DOI: 10.1016/ j.jphotochem.2017.07.024.

42 The Pharmacopeia Committee of Ministry of Health PR China, The Pharmacopeia of $P R$ China, China medical science Press, Beijing, 2nd edn, 2015, p. 875. 